\title{
Age at First Marriage and First Birth Interval in Ethiopia: Analysis of the Roles of Social and Demographic Factors
}

\author{
Eshetu Gurmu ${ }^{1}$ and Dula Etana \\ Centre for Population Studies, Addis Ababa University, Ethiopia
}

\begin{abstract}
The ages at which females establish marital union and give first birth depend on and result in varying demographic features. Utilizing the Ethiopian Demographic and Health Survey Data, this study examined determinants of first birth interval. The analysis was made using Cox proportional hazard model and Kaplan Meier plot based on data collected from 10,240 ever-married women in the age group 15 to 49. The result shows that first marriage at early age, lower level of education, older marriage cohort, and residence in Amhara region significantly elongated first birth interval. It reveals that timings of marriage and first birth are partly governed by social factors and marriage practices of the society although modernization factors have roles to play. The findings indicate the importance of considering the context within which marriage and first birth take place to address reproductive health problems of women and speed-up the achievement of the targets set in the National Population Policy of Ethiopia.
\end{abstract}

Keywords: age at first marriage, age at first birth, first birth interval, Ethiopia

\section{Résumé}

L'âge auquel les femmes établissent union conjugale et donnent naissance du premier enfant dépend et entraîner une variation des caractéristiques démographiques. Utilisant la démographie éthiopienne et des données de l'Enquête sur la santé, cette étude a examiné les déterminants de premier intervalle de naissance. L'analyse a été faite en utilisant Cox modèle de risque proportionnel et Kaplan Meier intrigue basée sur des données recueillies auprès de 10240 femmes non mariées dans la tranche d'âge de 15 à 49 . Le résultat montre que le premier mariage à un âge précoce, faible niveau d'éducation, les personnes âgées cohorte de mariages, et de séjour dans la région d'Amhara premier intervalle de naissance considérablement allongée. II révèle que les horaires de mariage et la première naissance est en partie régie par des facteurs sociaux et les pratiques matrimoniales de la société bien que les facteurs de modernisation ont un rôle à jouer. Les résultats indiquent l'importance de considérer le contexte dans lequel le mariage et la première naissance ont lieu de s'attaquer aux problèmes de santé reproductive des femmes et accélération de la réalisation des objectifs fixés dans la Politique nationale de la population de l'Ethiopie.

Mots clés: âge au premier mariage, l'âge à la première naissance, premier intervalle de naissance, l'Ethiopie

\footnotetext{
${ }^{1}$ Corresponding Author: eshetugurmu@gmail.com
} 


\section{Introduction}

Age at first marriage heralds the time of entry to marital life and regular exposure to the risk of child bearing (Islam 2009). Assuming that fertility often takes place within marriage and contraceptive practices are non-existent, there is an inverse relationship between age at first marriage and fertility. In Ethiopia, marriage is universal and occurs early (Ezra and Gurmu 2002). For instance, the proportion of women aged 25-49 who got married at age 18 was $70.2 \%$ in 2000 while it showed a slight decrease (i.e. 65.6\%) in 2005 (CSA and ORC Macro 200I, 2006). The social pressure to give birth is very strong upon the bride and withstanding this pressure is nearly impossible, given the high values of children (Eyayou et al. 2004). In addition, parents' enthusiastic interest to prove fecundity of daughters as a means to ensure sustainability of marriage is another factor perpetuating child bearing soon after marriage. Contrary to this expectation, there is a delay in age at first birth. According to the 2005 Ethiopian Demographic and Health Survey (EDHS), the median age at first birth was 19 years for women in the age group 25 to 49 , showing a lag of 3 .I years between entry into first marriage and first birth. Similar pattern is observed in the $2000 \mathrm{EDHS}$.

Ethiopia is experiencing low but steadily increasing contraceptive prevalence rate (CPR). CPR was only $8.1 \%$ in 2000 but increased to $14 \%$ in 2005 (CSA and ORC Macro 200I, 2006). There is also enormous variation of contraceptive use among different population groups in terms of socioeconomic status, place of residence, and regional locations (CSA and ORC Macro 2006). Despite such low CPR, there is a longer birth interval between marriage and first birth - the first birth interval. The median length of first birth interval was more than three years in some of the regions but less than two years in others. The conundrum, therefore, is why the interval between first marriage and birth is longer in a population that experiences early marriage and low contraceptive use with strong traditional norms and values that perpetuate high psycho-social and economic values of children (Eyayou et al. 2004; Malmberg and Tegenu, 2007).

The National Population Policy of Ethiopia targets the reduction of fertility to 4.0 in 2015 (National Office of Population 1993). Assuming the predominant occurrence of birth in marital union, increasing age at first marriage is believed to delay time of first birth. Although numerous studies (Kinfu 2000; Pathfinder Ethiopia 2006) investigated factors affecting the timing of marriage, little has been done on the relationship between the timings of first marriage and first birth. The purpose of this paper is, therefore, to examine socio-economic and demographic factors that determine the interval between first marriage and first birth and the mechanism by which these factors operate in the Ethiopian context. Specifically, it attempts to investigate whether early marriage leads to early child birth or not, and provide explanations attributing to such relationship.

\section{Theoretical considerations}

Modernization theory argues that socio-economic development affects age at first marriage through self-selection of spouses and economic independence of women (Malhotra and Tsui 1996). The shift from arranged to love marriage due to changes in socio-cultural setting obliterates parental roles in making decisions on the timing of marriage and child bearing. According to their view, marriage that is based on self-selection of a partner takes longer time to search for "appropriate" mate, which involves trial and error. Moreover, marriage that is based on free selection of mates involves premarital sexual relations. Given low CPR, this results in shorter birth intervals since the changes in traditional norms and values that dictate early marriage to ensuring virginity of girls upon marriage are abolished due to modernization elements (UN 1988; Malhotra and Tsui 1996).

In a study conducted to assess the length of first birth interval among young Chinese couples, Feng and Quanhe (1996) argued that four modernizationrelated social transformations change couple's sexual behaviour and timings of first marriage and first birth. These are: (a) the decline in arranged marriages, (b) rapid increase in formal education and nonfamilial employment, (c) changes in norms related to sexuality due to exposure to media, and (d) government's family planning program. The shift from arranged marriage to love marriage in China has resulted in the shortening of first birth interval, which Hong (2006) attributed to increased intimacy and coital frequency. Shrestha (1998), who conducted a similar study in Nepal, also argued that temporal change in the first birth interval is strongly influenced by social transformation which encourages quicker intimacy between couples.

The theory of marital instability (Becker et al. 1977), emphasizing the maximization of marriage utility with due consideration to the mediating effects of socio-economic and demographic factors, argues that loss of utility gain from marriage leads to marriage instability and hence dilutes the mediating 
factor of marriage (i.e. birth). On the other hand, the occurrence of birth and late marriage, Becker and Colleagues argue, reduce the probability of marital dissolution and vice versa. In a study conducted to test hypotheses derived from Becker's theory of marital instability, Huber and Spitze (1980) found that wives' thoughts of divorce decrease with age at first marriage and marital duration and that of husbands decrease with marital duration and age differences. It implies that the extent of marital stability in a given society has an impact on first birth interval. Those who wish to dissolve the marriage elongate the timing to first birth and vice-versa. Similar results were obtained in studies conducted in China (Feng and Quanhe 1996) and Nepal (Suwal 200I).

Empirical works on the effects of marriage instability due to early marriage on timing of first birth that are conducted in China (Feng and Quanhe 1996), India (Kumar and Danabalan 2006), and Bangladesh (Islam 2009) documented the mediating effects of socio-economic, demographic, and cultural characteristics of marriage partners. The analysis of first birth interval is crucial due to its demographic (Kumar and Danabalan 2006), health (Ezra and Gurmu 2002), and socio-economic (Ermisch and Pevalin 2005) implications. It is, therefore, imperative to study determinants of first birth interval in Ethiopia on the ground that there is social pressure to prove couple's fertility soon after marriage in communities that have limited access to family planning services. If shorter birth interval is a response to the catch-up effects of late marriage, an inverse relationship between length of first birth interval and factors affecting the timing of first marriage would be expected. Consequently, there is a need to control for the effects of individual characteristics such as education and residence type whilst investigating the relationship between age at first marriage and first birth. This is vital since the interplay between the timing of marriage and first birth rests not only on individual characteristics affecting fertility but also on societal approval to have children.

\section{Data and methods}

The data used in this study were drawn from the 2005 EDHS. The analysis, covering the entire regional states and city administrations, targeted 10,240 ever-married women aged 15-49 years. In this analysis, the marital-conception-first birth sequence was used as a dependent variable to define the first birth interval. Though premarital conception and premarital birth could lead to first birth, these sequences were not considered as their chances of occurrence were rare in Ethiopia, where birth outof-wedlock has no societal acceptance (Kinfu 2000; Molla et al. 2008; Ayalu and Lindstrom, 2014). As consensual union (living together before formally getting married) and the time gap between marriage ceremony and marriage registration is limited to major urban towns (if any), its effect on first birth interval would be minimal. Due to lack of detailed information on marriage history, it was not possible to run separate analysis for women married only once, as divorced women without children cannot be censored upon dissolving the first marriage.

The demographic and socio-economic variables considered as predictors of first birth interval were age at first marriage, place of residence, marriage cohort, women's educational attainment, and region. These variables were selected based on the findings of previous works (Feng and Quanhe 1996; Suwal 200I; Hong 2006; Islam 2009) and their potential roles in influencing the timing of first marriage and first birth. The variables were categorized for analysis as shown in Tables I and 2. Region is classified into six categories for there were few cases for some of the regions. These are Tigray, Amhara, Oromia, Southern Nations, Nationalities and Peoples (SNNP), eastern peripheral referring to the pastoralist dominant Afar and Somali regions, western peripheral representing the semi-pastoralist and pastoralist regions of Gambella and BenishangulGumuz, and others consisting of the Harari region and Addis Ababa and Dire Dawa city administrations that are mostly urban. Although first births could be delayed as a result of contraceptive use, the effect of family planning use was not controlled for, as the interval was computed for some times in the past whereas information on use of contraceptive referred to the survey period. The length of first birth interval is expected to be longer for women in rural areas, married early, older marriage cohort, and less educated. While women in urban areas are more exposed to education and labour force participation, they tend to marry late but give birth to a child soon after marriage.

In addition to descriptive statistics, Cox's proportional hazards model and Kaplan Meier's plot were applied to analyse the data. Kaplan-Meier life table (Kleinbaum and Klein 2005) was used to illustrate the differences in the first birth interval. The survival curve shows the probability of having first birth before or at the time of the survey. The life table method was applied to include censored observation with the assumption that women who did not give birth to a child were not systematically different 
from those who experienced the event (Kleinbaum and Klein 2005). The validity of this assumption was thus proved as a major portion of the cases were not censored. The Cox regression hazard model is a robust method of analysing birth intervals using life table technique (Rodriguez and Hobcraft 1980). The technique includes both closed and open birth intervals in the analysis to avoid the bias towards short intervals as a result of including only closed intervals. The proportional hazard model, which makes inferences about the underlying risk of observations on the timing of events, is expressed by the equation (Norusis 2007):

\section{$h(t)=[h o(t)] e^{(\beta 1 X 1+\beta 2 X 2+\cdots+\beta p X p}$}

Where $X_{1}$ to $X_{p}$ are the covariates, $\beta$ is a vector of unknown parameters, and $h_{0}(t)$ is the baseline hazard function for an individual with $X=0$ (Norusis 2007). In this study, the unit of analysis was the child bearing experience of a woman during the time elapsed between first marriage and first birth or the time of interview. The dependent variable was, therefore, whether or not birth had occurred during the interval. The case was coded 0 if the event (i.e. birth) did not occur or $I$ if it happened. For all cases that were censored by the year of interview, the observations were coded 0 on the dependent variable. Few cases pertaining to premarital births and shorter intervals (less than 7 months) were dropped. Intervals longer than 10 years were also excluded as some of these women, particularly those marrying early, may undergo sub-fecundity due to sexually transmitted infections and complications of pregnancies (Duncan et al. 1990).

\section{Results}

\section{Age at first marriage, intercourse, and birth}

In Ethiopia, sex out of wedlock is not socially approved (Molla et al. 2008). Individuals are expected to have sex after entering into marital union. As shown in Table I (Panel IV-VI), age at first marriage in the country exactly coincided with age at first sexual intercourse in all regions. No variation was also observed between median age at first marriage and first intercourse by age group and place of residence. However, there was slight difference between age at first intercourse and first marriage for women with higher level of education. The median age at first intercourse was one year earlier than the median age at first marriage for women whose educational level was secondary and above. Despite such slight deviation, the results generally indicated that sexual debut before marriage was negligible in Ethiopia, and consequently, the occurrences of conception and first birth before marriage were quite limited. The subsequent investigations were thus confined to the analyses of the first birth interval which resulted from conception after marriage.

\section{Differentials in median length of first birth interval}

It is evident from the Kaplan-Meier's plots that there were considerable differences in first birth interval. The difference was two years in rural areas but it was shorter by three to five months in other urban areas and Addis Ababa, respectively (Table I Panel VII), indicating that urban residents tended to have a child shortly after first marriage. The median interval between first marriage and first birth was longer in Amhara region (about 3.4 years), but it was shorter in Oromia, SNNP, and eastern peripheral regions (about I.7 years). The proportion of women who had not had the first birth in about five years after first marriage was more than $30 \%$ in Amhara region, about $20 \%$ in Tigray region, but about $10 \%$ in Oromia and SNNP regions (Fig lb). 
Table I: Number of women, proportion ever-married, still living in first marriage, had a child and median ages at first intercourse, marriage, and birth in Ethiopia

\begin{tabular}{|c|c|c|c|c|c|c|c|c|}
\hline \multirow{3}{*}{ Variables } & \multirow{3}{*}{ Categories } & \multirow{2}{*}{$\begin{array}{l}\text { Number of Ever- mar- } \\
\text { ried women }\end{array}$} & \multicolumn{2}{|c|}{$\%$ of ever married women } & \multicolumn{3}{|c|}{ Median age at first } & \multirow{2}{*}{$\begin{array}{l}\text { Median interval between } \\
\text { marriage and fist birth } \\
\text { (in months }\end{array}$} \\
\hline & & & $\begin{array}{l}\text { still living in } \\
\text { first union }\end{array}$ & $\begin{array}{l}\text { bearing at least } \\
\text { one child }\end{array}$ & $\begin{array}{l}\text { Marriage } \\
\text { (in years) }\end{array}$ & $\begin{array}{r}\begin{array}{r}\text { Intercourse } \\
\text { years) }\end{array} \\
\text { (in }\end{array}$ & $\begin{array}{c}\text { Birth(in } \\
\text { years) }\end{array}$ & \\
\hline & & $\mathrm{I}$ & II & III & IV & $\bar{v}$ & $\overline{\mathrm{Vl}}$ & $\overline{\mathrm{VII}}$ \\
\hline \multirow{7}{*}{ Age group } & $15-19$ & 868 & 90.4 & 13.6 & 15.0 & 15.0 & 16.0 & 20.0 \\
\hline & $20-24$ & 1718 & 85.8 & 56.3 & 16.0 & 16.0 & 18.0 & 20.0 \\
\hline & $25-29$ & 2191 & 81.7 & 81.3 & 16.0 & 16.0 & 18.0 & 22.0 \\
\hline & $30-34$ & 1655 & 75.8 & 91.6 & 16.0 & 16.0 & 18.0 & 22.0 \\
\hline & $35-39$ & 1570 & 70.3 & 94.7 & 16.0 & 16.0 & 18.0 & 24.0 \\
\hline & $40-44$ & 1164 & 66.8 & 96.6 & 15.0 & 15.0 & 19.0 & 26.0 \\
\hline & $45-49$ & 1074 & 65.0 & 97.7 & 15.0 & 15.0 & 18.0 & 27.0 \\
\hline \multirow{5}{*}{$\begin{array}{l}\text { Marriage co- } \\
\text { hort }\end{array}$} & Before 1980 & 1559 & 61.3 & 98.0 & 14.0 & 14.0 & 17.0 & 31.0 \\
\hline & $1980-1989$ & 2745 & 68.3 & 98.0 & 15.0 & 15.0 & 18.0 & 26.0 \\
\hline & $1990-1994$ & 1860 & 76.5 & 97.1 & 15.0 & 15.0 & 18.0 & 23.0 \\
\hline & $1995-1999$ & 1922 & 84.4 & 93.9 & 16.0 & 16.0 & 18.0 & 21.0 \\
\hline & $2000-2005$ & 2154 & 93.2 & 65.4 & 17.0 & 17.0 & 19.0 & 16.0 \\
\hline \multirow{3}{*}{$\begin{array}{l}\text { Women's } \\
\text { education }\end{array}$} & No education & 7462 & 74.0 & 81.6 & 15.0 & 15.0 & 18.0 & 24.0 \\
\hline & Primary & 1609 & 82.3 & 47.5 & 16.0 & 16.0 & 18.0 & 20.0 \\
\hline & Secondary and above & 1169 & 89.0 & 38.9 & 19.0 & 18.0 & 20.0 & 18.0 \\
\hline
\end{tabular}




\begin{tabular}{|c|c|c|c|c|c|c|c|c|}
\hline \multirow{4}{*}{ Religion } & Orthodox & 47111 & 67.3 & 62.2 & 15.0 & 15.0 & 18.0 & 26.0 \\
\hline & Protestant & 1606 & 87.7 & 65.8 & 16.0 & 16.0 & 18.0 & 19.0 \\
\hline & Islam & 3590 & 84.3 & 72.6 & 16.0 & 16.0 & 18.0 & 21.0 \\
\hline & Others & 329 & 83.3 & 70.7 & 16.0 & 15.0 & 18.0 & 20.0 \\
\hline \multirow{3}{*}{$\begin{array}{l}\text { Place of } \\
\text { residence }\end{array}$} & Rural & 7859 & 76.2 & 74.7 & 15.0 & 15.0 & 18.0 & 24.0 \\
\hline & Urban & 1614 & 77.7 & 53.8 & 17.0 & 17.0 & 19.0 & 21.0 \\
\hline & Addis Ababa & 767 & 83.8 & 40.0 & 17.0 & 17.0 & 19.0 & 19.0 \\
\hline \multirow{7}{*}{ Region } & Tigray & 982 & 66.1 & 70.3 & 15.0 & 15.0 & 18.0 & 29.0 \\
\hline & Amhara & 1618 & 51.9 & 73.3 & 14.0 & 14.0 & 17.0 & 41.0 \\
\hline & Oromia & 1653 & 82.9 & 69.3 & 16.0 & 16.0 & 18.0 & 20.0 \\
\hline & SNNP & 1498 & 86.4 & 68.1 & 16.0 & 16.0 & 18.0 & 20.0 \\
\hline & Eastern Peripheral & 1241 & 89.0 & 76.5 & 16.0 & 16.0 & 19.0 & 20.0 \\
\hline & Western Peripheral & 1325 & 75.8 & 76.4 & 15.0 & 15.0 & 17.0 & 22.0 \\
\hline & Others & 1923 & 84.2 & 49.6 & 17.0 & 17.0 & 19.0 & 20.0 \\
\hline \multicolumn{2}{|l|}{ Total } & 10240 & 77.0 & 66.4 & 16.0 & 16.0 & 18.0 & 23.0 \\
\hline
\end{tabular}

Source: Computed by the authors from Demographic and Health Survey Data 
There was a consistent decline in first birth interval from older (2.5 years) to younger ( 1.3 years) marriage cohorts. The decline was associated with an increase in median age at first marriage from 14 years for the oldest marriage cohort (married before 1980) to 17 years for the recent marriage cohort (married between 2000 and 2005). Similar trend was observed in urban areas where an increase in age at first marriage was accompanied by a reduction in the time interval between age at first marriage and first birth (Table I Panel VII). a) Place of residence

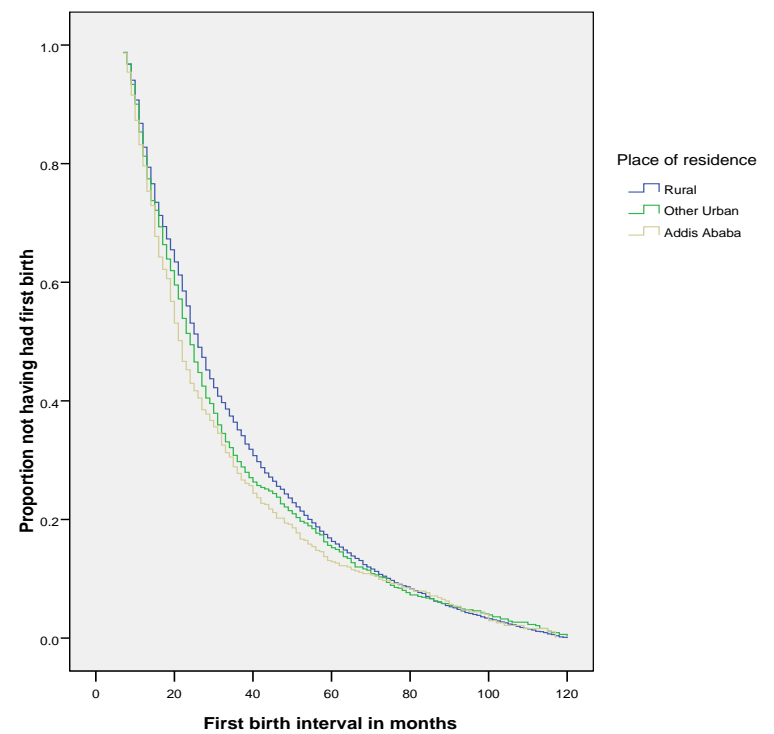

b) Region

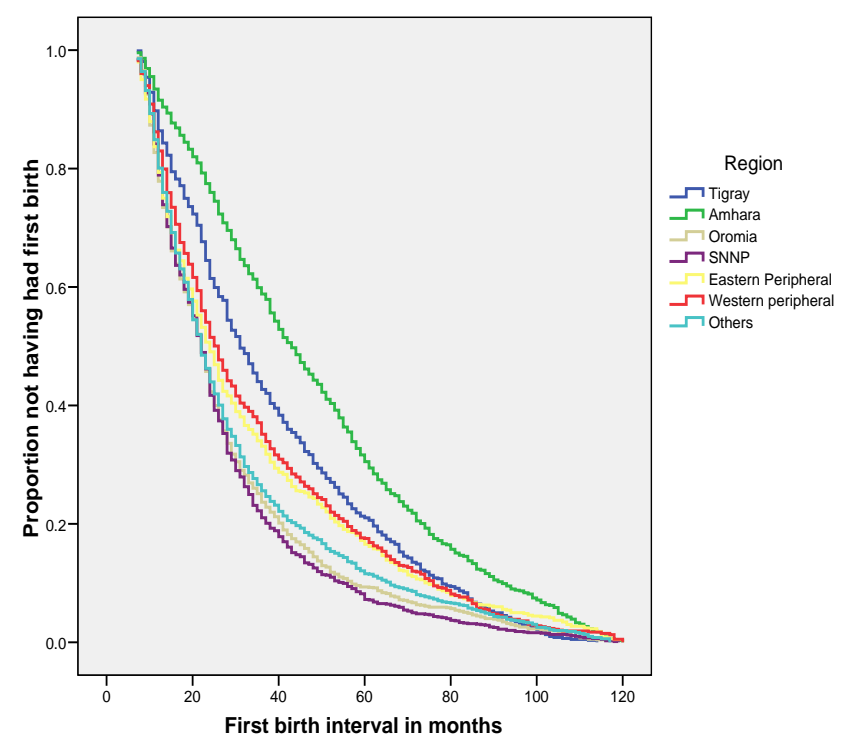

Fig. I: Kaplan-Meier plots showing proportion of women who had given birth to first child by (a) place of residence and (b) region.

The transition of women with no education to motherhood took longer time compared to the literates (Fig 2a). Uneducated women on average got married early (at age 15) whereas those who had secondary and higher education got married later (after 19) (Table I Panels IV and VI). First birth interval was longer for those who got married at early age (before age 15) but shorter for those who engaged in marital life after legal age of 18 years (Fig 2b). Among women who married before age 15, nearly $25 \%$ of them had not had first birth in about five years after marriage. The proportion was over $10 \%$ among those who married between age 15 and 17 , but less than $10 \%$ among those who married at later age. Difference in first birth interval was also observed among respondents belonging to different religious groups (Table I Panel VII). 
a) Respondent's education

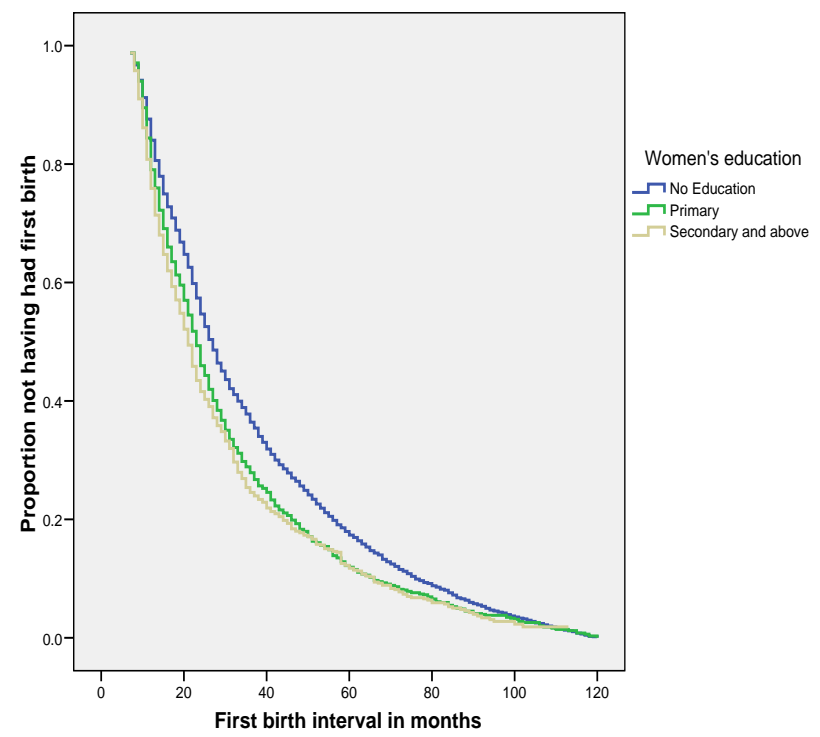

b) Age at first marriage

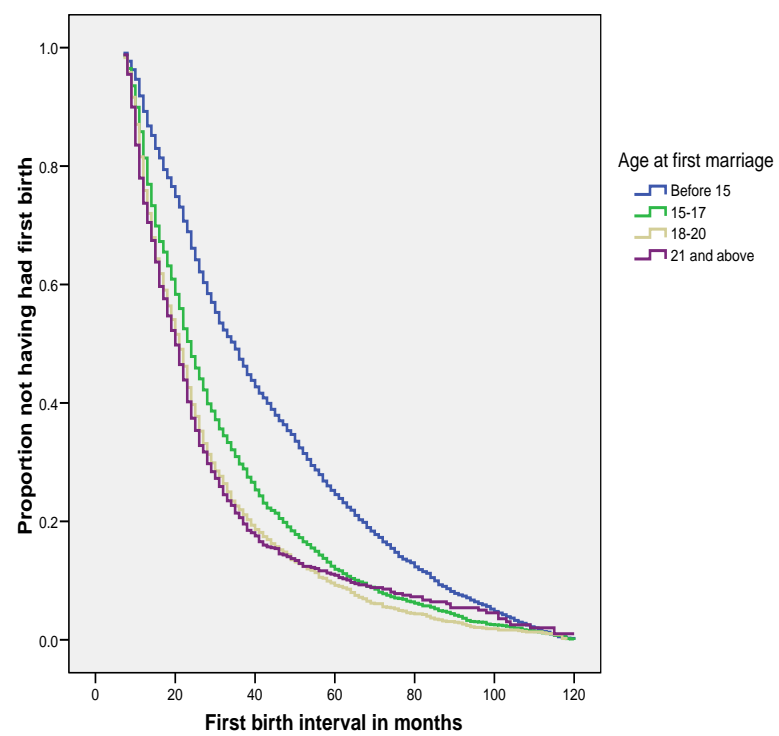

Fig. 2: Kaplan-Meier plots showing proportion of women who had given birth to first child by (a) respondent's educational level and (b) age at first marriage.

\section{Determinants of first birth interval: results of multivariate analysis}

The likelihood of having first birth immediately after first marriage was significantly higher in Oromia and SNNP regions compared to Amhara region (Table 2 Model V). For women in Oromia region, the likelihood of first birth soon after marriage had increased by $65 \%(\mathrm{p}<0.00 \mathrm{I})$ while it was $63 \%$ higher for women in SNNP region $(p<0.00 \mathrm{I})$. Considerable differences between the regions that exhibited higher chances of quick transition to motherhood were also manifested among respondents from Tigray, eastern and western peripheral regions, and other urban dominant regions. The chance of having first birth shortly after marriage had decreased by at least $14 \%$ for urban residents $(p<0.00 \mathrm{I})$ compared to women residing in rural areas probably due to aspiration for small family among urban residents. Protestant women had 17\% higher chances of having first birth soon after marriage $(p<0.00 \mathrm{I})$ than Orthodox Christians.

As expected, early marriage (marriage before age 18) had significant effect on the timing of first birth. The likelihood of having first child shortly after marriage was lower by $31 \%$ for those who got married before age 15 but lower by 13\% for those who entered into marital life between ages 15 and 17 compared to those who married between age 18 and 20. The pattern of relationship between age at first marriage and first birth interval was not changed even after controlling for the effect of educational level that was supposed to affect timing of first marriage (Table 2 Model $\mathrm{V}$ ), indicating that compensation for late start was not the only factor explaining the variation in the time of transition to motherhood. It further shows the important roles of other social and demographic factors in influencing the timing of first birth 
Table 2: Cox regression results of marriage to first birth interval for ever-married women in Ethiopia

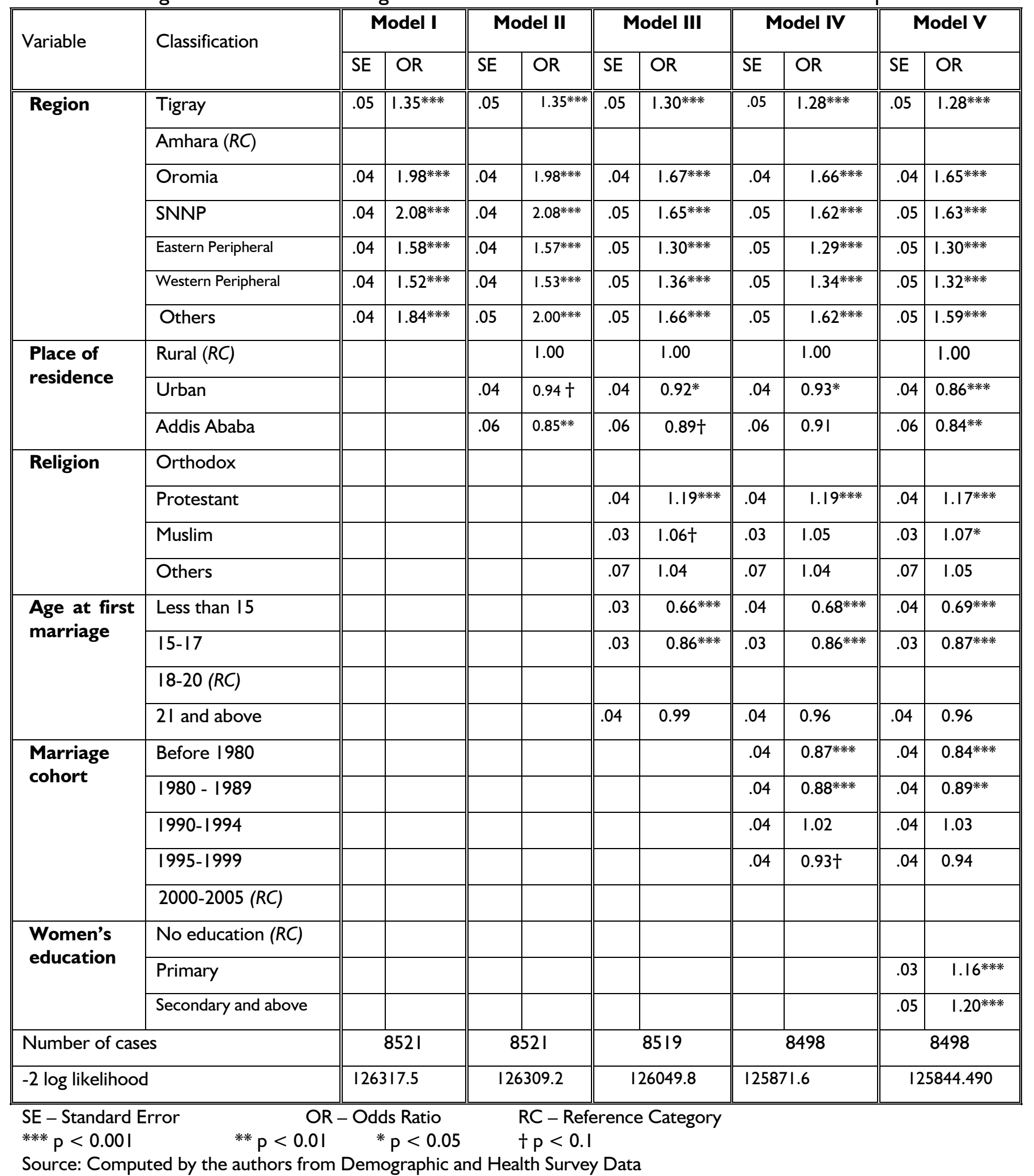

The likelihood of having the first child soon after marriage was reduced by at least $16 \%$ among the oldest marriage cohort (Table 2 Model IV). It was reduced to $11 \%$ for those women who got married between 1980 and 1989, compared to those who got married after 2000. Consistent with theoretical expectations, the interval between first marriage and first birth was shorter among those who spent some time in schooling than those who had never been to school. The chance of having fist birth was higher by $25 \%$ among those attaining secondary and higher education $(p<0.00 \mathrm{I})$ while it was higher by $16 \%$ among those who attended primary education $(p<0.05)$ compared to those with no education at all. 


\section{Discussion}

The results of this study generally show noticeable difference in the first birth interval by age of entry into marital life, region, marriage cohort, and educational attainment of respondents. Given the diverse geographical and cultural settings of the country, the variation in first birth interval can be explained by multiple theoretical perspectives. The theory of marital instability, for instance, seems to explain the differences in the time of transition to motherhood. The regional variation in first birth interval could be related to traditional norms and values governing the formation and stability of marriage, and consequently the interval between first marriage and first birth. Besides, modernization factors appear to gradually change the sexual and reproductive health behaviour of younger marriage cohorts. Policies and programmatic actions also play non-negligible roles in bringing changes in some aspects of the sexual and reproductive health behaviour of women.

Early marriage elongates the timing of first birth: Like findings in India (Nath et al. 1993), Nepal (Suwal 200I), and Bangladesh (Islam 2009), early marriage in Ethiopia is associated with longer first birth interval. Physiological, health, and social factors could possibly explain the longer interval between first marriage and first birth among those who got married early. At such young age, females are neither physically mature nor psychologically prepared to be a mother. Besides, marriage at an early age is mostly based on incomplete information and exaggerated expectations of husbands or wives and inlaws which make young brides feel discomfort about the marital union and may take actions to avoid or delay pregnancy (Erulkar et al. 2004). The young couples may not also have adequate knowledge about one another leading to uncertainty about the future of their marriage. Hence, first birth interval is influenced by the time required to establish close relationship and ensure sustainability of their marriage. Furthermore, early marriage and the consequent early sexual encounter is commonly associated with obstetric health complications such as fistula, leading to elongated timing of first birth. Gage and colleagues (2009) reveals that this problem is common in Amhara region and the risk is the highest among teenage who have their first pregnancies before age 15. Patterns of living arrangement after first marriage could also explain difference in first birth interval. Due to physical immaturity and psychological unpreparedness to manage household chores, girls who marry early often live with parents or mothers-in-law (Erulkar et al. 2004; Pathfinder
Ethiopia 2006). This has the potential to reduce coital frequency that would lead to conception and child birth.

Marriage system and transaction play crucial role in affecting the timing of first birth: Controlling for the effects of age at first marriage, first birth interval remains significantly longer in Amhara region than in others, indicating the roles of different marriage practices and customs in the postponement of the timing of first birth. The practice of marriage in this region is partly associated with ensuring socio-economic benefits cementing the relationship between two families. Families often promise to arrange for their children's marriage even before they have been conceived. This leads to a higher prevalence of arranged marriages. According to Pathfinder Ethiopia (2006), about 55\% of ever-married women in the region entered into union due to pressure that mainly came from parents. The same study indicated institutionalized tradition, poverty, protecting virginity, and avoiding premarital sex as additional causes of arranged marriage that mostly occurred early. These problems lead to prevalent problem of divorce (Pathfinder Ethiopia 2006). Marital instability in the region could lengthen the gap between first marriage and first birth. When either of the partners (particularly the bride) is suspicious of divorce/separation, it is very likely that it will take longer time to conceive as she could use any means to avoid or terminate pregnancy.

Unlike in Amhara, marriage in other regions such as Oromia and SNNP involves "give-and-take" of resources (Ezra and Gurmu 2002; Eyayou et al. 2004). Marriage in these regions is also costly (Beyene and Tolera 2006). In addition to ceremonial costs, parents provide various resources, household utensils, and ritual gifts to the newly married couples that lay basic economic foundation for their future marital life (Debsu 2009). In these regions, divorce is highly discouraged (Beyene and Tolera 2006; Debsu 2009). Moreover, the likely economic cause of divorce is limited due to the gifts given to the new marriage partners. Assortative mating involving commodity exchange at marriage puts women in better economic and decision making power to ensure marital stability (Fafchmps and Quisumbing 2004). Even though marriage based on give-and-take of resources leads to late entry into marriage, it makes the marriage more stable. In addition, the long process of union formation develops and strengthens relationship between the would-be 
couples. These cultural settings of marriage contribute to shorter first birth interval.

Higher level of education shortens the timing of first birth after marriage: Consistent with findings in India (Nath et al. 1993), China (Feng and Quanhe 1996), Nepal (Suwal 200I), and Ghana (Logubayom and Luguterah 20I3), women with higher educational attainment had shorter first birth interval. The relationship between education and length of first birth interval seems to be indirect. Increase in women's educational level in Ethiopia is associated with improved labour force participation, access to media, and enhanced social status (Kinfu 2000). These lead to changes in value orientations related to gender roles, women's autonomy, traditional roles of marriage, and norms of spouse selection (Mensch et al. 2005). High level of education results in weakening of traditional roles of parents in determining the marriage partner of their daughters and promotes self-selection of spouse which often takes longer time. It is true that highly empowered women are usually privileged to decide on not only whom and when to marry but also when to give birth. This social empowerment of women and the lengthy process of spousal selection are believed to strengthen the intimacy between marriage partners and thus allow them build strong confidence on each other, which, in turn, uplifts their eagerness to have a child to maximize marital satisfaction, leading to shorter first birth interval (Hong 2006). Moreover, education increases marital stability through secured financial resources (lkamari 2005). This is also believed to shorten first birth interval as, at the time of entry to marital life, they are emotionally prepared, biologically mature, and financially secured to have a child.

Decline in the length of first birth interval among the younger marriage cohorts is a signal of response to policy and programmatic interventions: Similar to the finding in China (Feng and Quanhe 1996), women in more recent cohorts had shorter first birth interval. The National Population Policy of Ethiopia (National Office of Population 1993) and the Family Law (Federal Democratic Republic of Ethiopia 2000) strictly prohibit marriage before age 18. The policy aimed at reducing fertility through provision of modern contraceptive supplies to all women of reproductive ages and providing more opportunities for girl's education. To this end, local administrators, religious and community leaders, schools, civil societies and different government as well as non-government organizations have involved in the campaign against early marriage (Path- finder Ethiopia 2006). Consequently, the mean age at first marriage had significantly increased by two years for the younger marriage cohort (married after adoption of the policy) compared to the older marriage cohort (married before the year of policy adoption) which was 15.2 years (Result not shown). This change in the age of entry to marital life is thus partly the result of the concerted efforts of various stakeholders working on population and development issues in the country.

Nevertheless, the mean age at first birth had increased by only one year for the younger marriage cohort. This indicates that although the policy is expected to increase both age at first marriage and first birth, it has noticeable effect on the former but not on the latter. As a result, the interval of transition to motherhood has shown a declining trend. First birth interval had decreased significantly from about 36 months for older cohort to 27 months for the younger cohort. Had there been a proportional increase in age at first birth, there would have been a corresponding increase in the first birth interval. This declining trend of first birth interval has its own policy and programmatic implications in order to achieve the demographic targets set in the National Population Policy of Ethiopia.

\section{Conclusions}

This study attempted to investigate determinants of first birth interval in Ethiopia. The findings indicate that sexual and reproductive behaviour of adolescents in general and the timing of first birth in particular is mainly a function of age of entry to marital union, cultural practices with regard to the pattern of family formation, educational attainment of women, and limited policy influences on age at first birth. Although increasing age at first marriage is commonly stated as a means to reduce fertility and improve the reproductive health situation of mothers, the findings indicate that there are conditions in which socio-cultural factors contribute to differences in fertility behaviour. In Amhara region where marriage takes place early, partly for cultural reasons, the time of transition to motherhood is longer. This early marriage, coupled with high risk of divorce in the region, appears to compel the women to delay first birth to avoid the burden of single parenthood. Besides, the physiological immaturity of those married at younger age delays age at first birth more than other regions where the socio-economic and cultural settings allow couples to enter into marital life late and give first birth soon. 
Modernization elements that promote cultural changes and new orientation of the youth on sexual and reproductive matters seem to have influence on the newly emerging patterns of marriage and fertility that subsequently affect the length of first birth interval. This is evident from shorter birth interval among highly educated women and younger marriage cohort. With expansion of education, it is more likely that the youth undermine the traditional marriage norms and values that encourage early marriage and birth. This often delays age at first marriage. When age at first marriage rises, couples often bear their first child soon after marriage not only to compensate for their late start but also to prove maternal fertility. Their likely economic security and need to ensure that they would have enough time to achieve their desired fertility also hasten their entry into motherhood shortly after marriage.

Longer first birth interval is expected to reduce the total fertility rate of a woman. Hence, in the limited prevalence of contraceptive use, improvement in women's socio-economic conditions is essential to bring changes associated with reducing fertility and improving maternal and child wellbeing through elongated birth interval. If age at first marriage does not necessarily coincide with age at first sexual debut, as shown in this study, attempting to increase age at first marriage alone does not necessarily yield the required demographic outcome (low fertility). Hence, the attempt to reduce fertility by increasing age at first marriage shall consider the socio-economic and cultural settings within which marriage takes place. On the other hand, the fight against early marriage shall target not only reducing fertility but also addressing its socio-cultural, physiological, and psychological impacts. However, the effects of early marriage on or contribution of late marriage to completed family size require further investigation. The relationship between age at first marriage, marital instability, and subsequent births and the effects of modernization on family formation and reproduction also require in-depth study.

\section{Acknowledgments}

We would like to gratefully acknowledge the Central Statistical Agency of Ethiopia and ORC Macro for allowing us to use DHS dataset to undertake this study. The comments of the anonymous reviewers and the editor were highly crucial to shape the article in its present form. We also thank Mr. Teshome Dhaba for diligently editing the article.

\section{References}

Ayalu, A. and Lindstrom, D. 2014. "Recent Trends in the Timing of First Sex and Marriage among Young Women in Ethiopia" African Population Studies 28, (2 supplement): II 157 - II 70.

Becker, G.S., Landes, E.M., and Michael, R.T. 1977. "An Economic Analysis of Marital Instability" Journal of Political Economy 85, (6): I | 4 I- I I 87.

Beyene, G. and Tolera, A. 2006. "Marriage Practices among the Gidda Oromo, Northern Wollega, Ethiopia" Nordic Journal of African Studies 15, (3): 240-255.

Central Statistical Authority and ORC Macro 2006. Ethiopia Demographic and Health Survey 2005. Addis Ababa, Ethiopia and Calverton, Maryland, USA: Central Statistical Agency and ORC Macro.

Central Statistical Authority and ORC Macro $200 \mathrm{I}$. Ethiopia Demographic and Health Survey 2000. Addis Ababa, Ethiopia and Calverton, Maryland, USA: Central Statistical Agency and ORC Macro.

Debsu, D. 2009. "Gender and Culture in Southern Ethiopia: An Ethnographic Analysis of GujiOromo Women's Customary Rights" African Study Monographs 30, (I): 15-36.

Duncan, M.E., Tibaux, G., Pelzer, A., Reimann, K., Peutherer, J., Simmonds, P., Yound, H., Jamil, R. and Darroughar, S. 1990. "First Coitus before Menarche and Risk of Sexually Transmitted Disease" Lancet 335: 338-340.

Ermisch, J. and Pevalin, D.J. 2005. "Early Motherhood and Later Partnerships" Journal of Population Economics 18, (3): 469-489.

Erulkar, A.S., Mekbib, T., Simie, N. and Gulema, T. 2004. The experience of adolescence in rural Amhara Region, Ethiopia. The Population Council.

Eyayou, Y., Berhane, Y. and Zerihun, L. 2004. "Socio-cultural Factors in Decisions Related to Fertility in Remotely Located Communities: The Case of the Suri Ethnic Group" Ethiopian Journal of Health Development 18, (3): I7I-I74.

Ezra, M. and Gurmu, E. 2002. "Correlates of Marriage and Family Patterns in Southern Ethiopia" Ethiopian Journal of Development Research 24,(I):58-91.

Fafchamps, M. and Quisumbing, A.R. 2004. Assets at marriage in rural Ethiopia. IFPRI Discussion Paper 185.

Federal Democratic Republic of Ethiopia 2000. Revised family law of Ethiopia. Addis Ababa.

Feng W. and Quanhe, Y. 1996. "Age at Marriage and the First Birth Interval: The Emerging Change in 
Sexual Behaviour among Young Couples in China" Population and Development Review 22, (2): 299-320.

Gage, A., Berhane, Y. and Worku, A. 2009. "Consequences of early marriage" In Coverage and effects of child marriage prevention activities in Amhara Region, Ethiopia: Findings from a 2007 study, Edited by Gage, A. USAID, MEASURE Evaluation, and Addis Continental Institute of Public Health.

Hong, Y. 2006. "Marital Decision-making and the Timing of First Birth in Rural China before the 1990s" Population Studies 60, (3): 329-34I.

Huber, J. and Spitze, G. 1980. "Considering Divorce: An Expansion of Becker's Theory of Marital Instability" American Journal of Sociology 86, (I): 75-89.

Ikamari, L.D.E. 2005. "The Effect of Education on the Timing of Marriage in Kenya" Demographic Research 12, (I): I-28.

Islam, S. 2009. "Differential Determinants of Birth Spacing Since Marriage to First Live Birth in Rural Bangladesh" Pertanika Journal of Social Science and Humanities 17, (I): I-6.

Kinfu, Y. 2000. "Below Replacement Fertility in Tropical Africa? Some Evidence from Addis Ababa" Journal of Population Research 17, (I): 63-82.

Kleinbaum, D.G. and Klein, M. 2005. Survival analysis: A self-learning text. Second Edition. Springer Science and Business Media, Inc.

Kumar, G. and Danabalan, M. 2006. "Determinants of Delayed First Birth" Indian Journal of Community Medicine 3I (4).

Logubayom, I.A. and Luguterah, A. 2013. "Survival Analysis of Time to First Birth after Marriage" Research on Humanities and Social Sciences 3, (12): I 17-125.

Malhotra, A. and Tsui, A. 1996. "Marriage Timing in Sri Lanka: The Role of Modern Norms and Ideas" Journal of Marriage and Family 58, (2): 476-490.
Malmberg, B. and Tegenu, T. 2007. "Population Pressure and Dynamics of Household Livelihoods in an Ethiopian Village: An Elaboration of the Boserup-Chayanovian Framework" Population and Environment 29, (2): 39-67.

Mensch, B.S., Singh, S. and Casterline, J.B. 2005. Trends in the timing of first marriage among men and women in the developing world. Policy Research Division Working Paper No. 202, Population Council.

Molla, M., Berhane, Y. and Lindtjorn, B. 2008. "Traditional Values of Virginity and Sexual Behaviour in Rural Ethiopian Youth: Results from a Crosssectional Study" BMC Public Health 8(9).

Nath, D.C., Singh, K.K., Land, K.C. and Talukdar, P.K. 1993. "Age of Marriage and Length of the First Birth Interval in a Traditional Indian Society: Life Table and Hazards Model Analysis" Human Biology 65, (5): 783-797.

National Office of Population 1993. National Population Policy of Ethiopia. Addis Ababa.

Norusis, M.J. 2007. SPSS 15.0: Advanced statistical procedures companion. Prentice Hall Inc.

Pathfinder Ethiopia 2006. Report on causes and consequences of early marriage in Amhara region. Addis Ababa, Ethiopia.

Rodriguez, G. and Hobcraft, J. 1980. Illustrative analysis: Life-table analysis of birth intervals in Colombia. Scientific Reports No. 16. World Fertility Survey, London.

Shrestha, D.P. 1998. "Socio-economic Changes, Women's Autonomy, and Timing of First Birth in a Semi-urban Community in Nepal" Nepalese Studies 25, (Special Issue): I29-143.

Suwal, J.V. 200I. "Socio-cultural Dynamics of Birth Intervals in Nepal” Nepalese Studies 28, (I): II33.

United Nations 1988. First marriage: Patterns and determinants. Report by Department of International Economic and Social Affairs. New York. 